\title{
SOME DISCUSSION ISSUES OF THE EARLY NEOLITHIC STUDY IN THE FOREST-STEPPE VOLGA REGION
}

(C) 2017

\author{
Andreev Konstantin Mikhailovich, candidate of historical sciences, \\ associate professor of Russian History and Archeology Department \\ Samara State University of Social Sciences and Education (Samara, Russian Federation)
}

Abstract. The PhD thesis «The early Neolithic of the forest-steppe Volga region» was presented by the author of this annotation on December, 15th. Some of the statements presented were taken into consideration on the basis of received reviews and a number of special works of concerned researchers. The following paper deals with some issues that are clarified and some problems referring to the study of this topic that are raised. It is strongly believed that only a discussion on a wide range of key issues will contribute to a better understanding of cultural and historical processes taking place in the reporting period in the region. One of the most controversial issues in the study of the early forest-steppe Neolithic is chronology. We confirm the idea that Neolithic process in this region started at the beginning of the VII millennium BC. There are additional justifications that elshanskaya culture was divided into two types. We implement a critical analysis of the hypotheses related to the search for the origins of early Neolithic ceramic traditions. It is also claimed that the process mentioned is connected with the Central Asian region. Another problem is connected with the formation of a ceramic lygovskoy type and the influence of Neolithic groups in the Lower Volga region.

Keywords: forest-steppe Volga Region; early Neolithic; elshanskaya culture; absolute chronology; radiocarbon dating; neolithisation; kelteminar culture; western and eastern variants of elshanskaya culture; surskaya culture; rakushechnoyarskaya culture; lygovskoy type of ceramic; Lower Volga Region.

УДК 902

\section{ТЕХНОЛОГИЧЕСКИЙ АНАЛИЗ КЕРАМИКИ ЭПОХИ РАННЕЙ БРОНЗЫ ПОСЕЛЕНИЯ ШАУКЕ 1}

\section{(C) 2017}

Рахимжанова Сауле Жангельдыевна, аспирант кафедры археологии, этнографии и музеологии Алтайский государственный университет (2. Барнаул, Российская Федерация)

Аннотация. В статье излагаются первые результаты специального технологического изучения керамики эпохи ранней бронзы из раскопок поселения Шауке 1 в Павлодарской области Северо-Восточного Казахстана. Исследование керамики проведено в рамках историко-культурного подхода по методике А.А. Бобринского. Для проведения технологического анализа керамики поселения было отобрано 53 образца от разных сосудов, исследованных с помощью бинокулярного микроскопа МБС-10. Основная задача в работе сводилась к выявлению культурных традиций на подготовительной стадии изготовления керамики. Изучались навыки отбора исходного сырья и подготовки формовочных масс. Автором зафиксировано использование гончарами нескольких условных «мест» добычи сырья. На поселении Шауке 1 было выделено 6 разных рецептов формовочных масс, среди которых наиболее массовыми являются «глина + шамот + органический раствор» $(60,38 \%)$, «глина + шамот + кость + органический раствор» $(28,30 \%)$, что свидетельствует о бытовании на поселении носителей разных гончарных традиций. Также был проведен сравнительный анализ типологических орнаментальных групп керамики с полученными технологическими данными. В результате сравнения были определены как общие, так и специфические черты формовочных масс выделенных групп.

Ключевые слова: эпоха ранней бронзы; поселение Шауке 1; Северо-Восточный Казахстан; керамика; историко-культурный подход; методика А.А. Бобринского; технологический анализ; подготовительная стадия производства; исходное сырье; формовочные массы; гончарные традиции.

Керамика эпохи ранней бронзы на территории Северо-Восточного Казахстана очень слабо изучена. Ее исследование представляет собой особый интерес для всестороннего изучения и выявления особенностей и традиций изготовления керамики [1-4], а также сравнительного анализа с соседними регионами. Материалы данного поселения публикуются впервые.

Поселение Шауке 1 расположено в Павлодарском районе Павлодарской области на первой надпойменной террасе р. Иртыш в 0,5 км к северу от одноименного села на месте старого песчаного карьера. Памятник открыт В.К. Мерцем в 1992 году. В последующие 1996, 2001, 2006, 2011 годы отрядом ПАЭ на нем проводились регулярные сборы. Памятник явля- ется поселением древних скотоводов эпохи бронзы и раннего железа III-I тыс. до н.э. Разрушается песчаным карьером.

Керамика раннего бронзового века поселения Шауке 1 насчитывает 577 фр. (венчики - 59 шт., стенки - 462 шт., придонные части - 35 шт., не диагностируемые - 21 шт.) не менее, чем от 54 сосудов. Коллекция неоднородна, авторами раскопок и сборов поселения Шауке 1, В.К. Мерцем и И.В. Мерцем, выделено 4 группы керамики, украшенные способами: 1) «шагания» (орнаментир - гребенчатый штамп); 2) «протаскивания» и «отступающе-накольчатой» техникой (орнаментир - палочка); 3) «расчесами»; 4) «накалывания» (инструмент - гребенчатый штамп и палочка). 
1 и 3 группы керамики авторы раскопок соотносят с елунинской культурой Верхнего Приобья [5], 2 группу - с логиновским типом [6], 4 группа находит аналогии в одино-крохалевском керамическом комплексе [7].

Данная работа имеет целью реконструировать гончарные традиции населения эпохи ранней бронзы этого памятника на подготовительной стадии технологического процесса. В ходе исследования решались следующие задачи:

- выявление навыков отбора и обработки основного исходного пластичного сырья;

- выяснение навыков составления формовочной массы керамики;

- реконструкция культурных традиций в этих областях гончарной технологии и выяснение на этой основе степени культурной однородности их носителей.

Для технологического анализа керамики были отобраны фрагменты от 53 разных сосудов эпохи ранней бронзы поселения Шауке 1.

Исследование проводилось по методике, разработанной А.А. Бобринским $[8 ; 9]$ и его последователями [10-13] в рамках историко-культурного подхода. Наблюдения велись по свежим изломам черепков с помощью микроскопа МБС-10. Для определения степени ожелезненности исходного пластичного сырья применялся повторный обжиг небольших обломков каждого сосуда в муфельной печи при температуре $850^{\circ} \mathrm{C}$. После обжига черепки сравнивались по цвету с экспериментальной шкалой ожелезненности глин [14, с. 424].

Анализ проводился только по ступеням гончарной технологии, относящимся к подготовительной стадии производства: 1) отбор исходного сырья, 2) обработка исходного сырья и 3) составление формовочной массы.

В результате проведенного исследования были выявлена следующая технологическая информация.

Анализ исходного сырья. При изучении навыков отбора и подготовки исходного сырья было зафиксировано использование гончарами Шауке 1 трех видов глин: высокой пластичности (Гл. 1) - 37,74\%, средней пластичности (Гл. 2) - 49,06\%, низкой пластичности (Гл. 3) - 13,20\%. Для определения степени пластичности глины нами были использованы критерии размерности и концентрации примеси естественного песка, предложенные Е.В. Волковой [15]. Наиболее массово использовалась глина средней и высокой пластичности. По степени ожелезненности глины являются среднеожелезненными $(98,11 \%)$ и неожелезненными (Гл. 4) $(1,89 \%)$. Из естественных минеральных примесей в глине зафиксирован песок пылевидный (с размером частиц менее 0,5 мм), песок мелкий (от 0,5 до 0,9 мм), песок некалиброванный, песок средний (от 1,0 до 1,9 мм), бурый железняк.

Выявленные по степени пластичности и составу естественных примесей особенности глин позволяют предположить, что местные гончары использовали около 12 условных «мест» добычи (или вариантов) исходного пластичного сырья.

Ожелезненные глины:

Высокой пластичности:

I. Гл. $1+$ песок мелкий $(1: 6)-2$ сосуда $(3,77 \%)$,

II. Гл. $1-8$ сосудов $(15,1 \%)$,

III. Гл. $1+$ бурый железняк + песок мелкий (единичные включения) - 9 сосудов (16,98\%).
Средней пластичности:

IV. Гл. $2+$ песок пылевидный - 3 сосуда $(5,66 \%)$,

V. Гл. $2+$ песок мелкий -15 сосудов $(28,30 \%)$,

VI. Гл. 2 + песок пылевидный + бурый железняк 3 сосуда $(5,66 \%)$,

VII. Гл. $2+$ песок мелкий и средний + бурый железняк - 4 сосуда $(7,54 \%)$,

VIII. Гл. $2+$ песок некалиброванный -1 сосуд $(1,89 \%)$.

Низкой пластичности:

IX. Гл. 3 + песок пылевидный -4 сосуда $(7,55 \%)$,

Х. Гл. $3+$ песок мелкий и средний -2 сосуд $(3,77 \%)$

ХІ.Гл. 3 + песок некалиброванный -1 сосуд $(1,89 \%)$.

Неожелезненные глины:

Высокой пластичности:

XII. Гл. $4-1$ сосуд (1,89\%).

Во всех случаях исходное сырье использовалось в состоянии естественной влажности.

При анализе состава формовочных масс выделялись минеральные и органические искусственно введенные примеси (табл. 1). В качестве искусственных минеральных примесей использовались: шамот крупный $(2,0-2,9$ мм) и средний $(1,0-1,9$ мм) в концентрации 1:4-5; крупный $(2,0-2,9$ и более) в концентрации 1:4-5, средний (1,0-1,9 мм) в концентрации 1:5, некалиброванный в концентрации 1:3-4. В некоторых случаях в сосудах из ожелезненной глины зафиксировано использование шамота из ожелезненной и неожелезненной глины. Аналогичная ситуация в одном случае зафиксирована по сосуду, изготовленному из неожелезненной глины. Кроме того, в составе шамота из неожелезненной глины был обнаружен шамот из ожелезненной глины и наоборот - в шамоте из ожелезненной глины фиксируется шамот из ожелезненной глины; также в ряде случаев отмечена дресва некалиброванная в концентрации 1:5, дресва среднего размера (1,0-1,9 мм) в концентрации $1: 6$, дресва мелкая $(0,5-0,9$ мм) и средняя $(1,0$ 1,9 мм) в концентрации $1: 5$; кальцинированная кость мелкая (0,5-0,9 мм) в концентрации 1:6-7, мелкая $(0,5-0,9$ мм) и средняя $(1,0-1,9$ мм) в концентрации $1: 5-6$.

Таблица 1 - Сочетание искусственных минеральных примесей и глин разной пластичности в формовочной массе, число сосудов и \%

\begin{tabular}{|l|c|c|c|c|}
\hline \multirow{2}{*}{$\begin{array}{c}\text { птепень } \\
\text { пластичности } \\
\text { глины }\end{array}$} & \multicolumn{4}{|c|}{ Виды искусственных } \\
\cline { 2 - 5 } & Шинеральных примесей \\
\hline Шамот & $\begin{array}{c}\text { Шамот }+ \\
\text { кальци- } \\
\text { нирован- } \\
\text { ная кость }\end{array}$ & $\begin{array}{c}\text { Дре- } \\
\text { сва + } \\
\text { ша- } \\
\text { мот }\end{array}$ & Дресва \\
\hline Гл. Высокая & $18 / 33,96 \%$ & & & $1 / 1,89 \%$ \\
\hline Гл. 2. Средняя & $15 / 28,3 \%$ & $9 / 16,98 \%$ & $2 / 3,78 \%$ & \\
\hline Гл. 3. Низкая & $5 / 9,43 \%$ & $2 / 3,77 \%$ & & \\
\hline Гл. 4. Высокая & $1 / 1,89 \%$ & & & \\
\hline $\begin{array}{l}\text { Всего, число } \\
\text { сосудов }\end{array}$ & 39 & 11 & 2 & 1 \\
\hline Всего, \% & 73,58 & 20,75 & 3,78 & 1,89 \\
\hline
\end{tabular}

Из органических искусственных компонентов вносились органический раствор, который определяется по черному «жирному» блеску на поверхности минеральных включений и аморфным пустотам, 
стенки которых также покрыты налетом, навоз животных во влажном состоянии, представленный растительными отпечатками в виде хаотично расположенных пучков, пор овальной и аморфной формы с потеками на стенках, и органика неясного происхождения.

Обобщая всю полученную информацию о составе искусственных примесей, использовавшихся гончарами поселения Шауке 1, представляется возможным выделить 6 разных рецептов составления формовочных масс керамики:

- «глина + шамот + органический раствор» $(60,38 \%)$,

- «глина + шамот + кальцинированная кость + органический раствор» $(28,30 \%)$,

- «глина + шамот + навоз влажный» $(3,77 \%)$,

- «Глина + дресва + шамот + органический раствор» $(3,77 \%)$.

- «глина + дресва + органика» $(1,89 \%)$,

- «глина + шамот + органика» $(1,89 \%)$.

Последние 4 рецепта представлены в единичных случаях, а первые два являются массовыми. Причем первый рецепт скорее всего можно рассматривать как несмешанный, а в отношении второго вопрос по- ка остается открытым. По крайней мере, до тех пор, пока не будут обнаружены сосуды, где в формовочной массе присутствует, помимо глины, только примесь кальцинированной кости. Рецепты, представленные единично, все относятся к группе смешанных. Особенно явно это проявляется в рецепте «глина + дресва + шамот + органический раствор», где присутствуют две минеральные примеси, выполняющие одну и ту же функцию - повышение огнестойкости изделий [8, с. 90-96].

В ходе сравнения выделенных типологических орнаментальных групп с результатами технологического анализа было выявлено (табл. 2), что для 1-й группы керамики использовалось 5 рецептов формовочных масс. Наиболее массово использовался рецепт «глина + шамот + органический раствор» $(23,08 \%)$, реже «глина + кальцинированная кость + шамот + органический раствор» $(7,69 \%)$; «глина + шамот + навоз» $(5,77 \%)$. В единичных случаях зафиксировано использование рецептов: «глина + дресва + органика» $(1,92 \%)$, «глина + шамот + дресва + органический раствор» $(3,85 \%)$.

Таблица 2 - Корреляция рецептов формовочных масс и типологических орнаментальных групп керамики поселения Шауке 1

\begin{tabular}{|l|c|c|c|c|c|}
\hline \multirow{2}{*}{$\begin{array}{c}\text { Орнаментальные } \\
\text { группы }\end{array}$} & $\begin{array}{c}\text { Шамот }+ \\
\text { органический } \\
\text { раствор }\end{array}$ & $\begin{array}{c}\text { Шамот + кальциниро- } \\
\text { ванная кость + орга- } \\
\text { нический раствор }\end{array}$ & $\begin{array}{c}\text { Шамот }+ \\
\text { навоз }\end{array}$ & $\begin{array}{c}\text { Дресва }+ \\
\text { органика }\end{array}$ & $\begin{array}{c}\text { Шамот }+ \text { дресва }+ \\
\text { органический } \\
\text { раствор }\end{array}$ \\
\hline Группа 1,3 & $16 / 30,77 \%$ & $6 / 11,54 \%$ & $3 / 5,77 \%$ & $1 / 1,92 \%$ & $2 / 3,85 \%$ \\
\hline Группа 2 & $17 / 32,69 \%$ & $2 / 3,85 \%$ & & & \\
\hline Группа 4 & 33 & $5 / 9,61 \%$ & & & 2 \\
\hline Всего, сосудов & 63,46 & 13 & 3 & 1 & 3,85 \\
\hline$\%$ & 25 & 5,77 & 1,92 & \\
\hline
\end{tabular}

Для 2-й орнаментальной группы отмечен рецепт «глина + кальцинированная кость + шамот + органический раствор» $(3,85 \%)$.

При изготовлении сосудов 3-й орнаментальной группы использовались рецепты: «глина + шамот + органический раствор» $(7,89 \%)$, «глина + кальцинированная кость + органический раствор» $(3,85 \%)$.

Для керамики 4-й орнаментальной группы выделены рецепты «глина + шамот + органический раствор» $(32,69 \%)$, «глина + кальцинированная кость + шамот + органический раствор» $(9,61 \%)$.

Полученная информация позволяет сделать вывод о том, что керамика 1-й группы, где зафиксировано наибольшее количество разных рецептов, была наиболее неоднородной по традициям составления формовочный масс. Здесь присутствуют как смешанные, так и несмешанные рецепты. Причем можно предполагать, что рецепт «глина + дресва + шамот + органика» возник на этом поселении, поскольку здесь зафиксированы исходные для его образования рецепты: «глина + шамот + органический раствор» и «глина + дресва + органика». Керамика других орнаментальных групп имеет как общие, так и специфические рецепты формовочных масс. В целом, население этого памятника было достаточно неоднородным по составу изученных гончарных традиций.

В ходе изучения керамики эпохи ранней бронзы на территории Северо-Восточного Казахстана сравнительный анализ навыков подготовки формовочных масс показал, что наиболее близкие аналогии данная керамика находит с керамикой поселения Березовая Лука [16] и погребальной посудой могильника Телеутсткий Взвоз-I [17] елунинской культуры на Алтае, которая составляет в коллекции поселения Шауке 1 $53,8 \%$ сосудов. На этих памятниках, так же как и на поселении Шауке 1 , основной искусственной минеральной примесью является шамот. На поселении Березовая Лука шамот составляет $74 \%$ случаев, шамот в сочетании с дресвой - $16 \%$, только дресва 10\%. Такие данные были получены В.А. Борисовым для керамики с отступающе-накольчатой орнаментацией. Для шагающей техники орнаментации характерна другая рецептура, согласно которой основной примесью являлись песок и дресва $(84 \%)$, шамот составляет меньший процент $(7,7 \%)$ [18; 19]. На казахстанских памятниках эпохи ранней бронзы случаев с искусственно добавленным песком в качестве примеси не встречено. В 20\% случаев встречена кальцинированная кость на керамике могильника Телеутский Взвоз-I, на поселении Березовая Лука рецептов с добавлением кальцинированной кости не выявлено $[16 ; 17 ; 19 ; 20]$. Дальнейшее изучение технологии изготовления керамики эпохи ранней бронзы на территории Северо-Восточного Казахстана имеет перспективы в связи с неизученностью данного источника на этой территории.

Автор выражает глубокую благодарность В.К. Мерцу и И.В. Мерцу за возможность работы с неопубликованными материалами. 


\section{СПИСОК ЛИТЕРАТУРЫ:}

1. Мерц В.К. К изучению памятников эпохи ранней бронзы Казахстана // Археологические исследования в Казахстане: тр. науч.-практ. конф. «Маргулановские чтения - 14». Шымкент, 2002. С. 34-41.

2. Мерц В.К. О новых памятниках эпохи ранней бронзы Казахстана // Исторический опыт хозяйственного и культурного освоения Западной Сибири. Барнаул, 2003. С. 132-141.

3. Мерц В.К. Новые материалы по энеолиту и ранней бронзе северо-восточного Казахстана // Новые исследования по археологии Казахстана: тр. науч.-практ. конф. «Маргулановские чтения». Алматы, 2004. С. 165-169.

4. Мерц И.В., Мерц В.К. Новые материалы раннего бронзового века из Западной части Кулундинской равнины // Сохранение и изучение культурного наследия Алтайского края. Барнаул, 2013. С. 207214.

5. Кирюшин Ю.Ф. Энеолит и ранняя бронза юга Западной Сибири: монография. Барнаул: АлтГУ, 2002. $294 \mathrm{c}$.

6. Стефанова Н.К. Кротовская культура в Среднем Прииртышье // Материальная культура древнего населения Урала и Западной Сибири. Свердловск: УрГУ, 1988. С. 53-75.

7. Полосьмак Н.В. Керамический комплекс поселення Крохаловка-4 // Древние культуры Алтая и Западной Сибири. Новосибирск, 1978, С. 36-40.

8. Бобринский А.А. Гончарство Восточной Европы. Источники и методы изучения. М., 1978. 272 с.

9. Бобринский А.А. Гончарная технология как объект историко-культурного изучения // Актуальные проблемы изучения древнего гончарства (колл. моногр.). Самара: Изд-во СамГПУ, 1999. С. 5-109.

10. Волкова Е.В. Гончарство фатьяновских племен. М., 1996. 116 c.

11. Цетлин Ю.Б. Неолит центра Русской равнины: орнаментация керамики и методика периодизации культур. Тула: Гриф и К, 2008. 352 с.

12. Васильева И.Н., Салугина Н.П. Работы экспедиции по экспериментальному изучению древнего гончарства // Вопросы археологии Урала и Поволжья. Вып. 1. Самара: СамГПУ, 1999. С. 234-257.

13. Степанова Н.Ф. Особенности исходного сырья и формовочных масс керамики эпохи неолита и бронзы Горного Алтая и его северных предгорий // Древнее гончарство: итоги и перспективы изучения. M., 2010. C. 117-125.

14. Цетлин Ю.Б. Об определении степени ожелезненности исходного сырья для производства глиняной посуды // Вопросы археологии Поволжья: Выпуск 4. Самара: Изд-во «Научно-технический центр», 2006. C. 421-425.

15. Лопатина О.А., Каздым А.А. О естественной примеси песка в древней керамике (к обсуждению проблемы) // Древнее гончарство: Итоги и перспективы. М., 2010. С. 46-57.

16. Грушин С.П., Кирюшин Ю.Ф., Тишкин А.А. и др. Елунинский археологический комплекс Телеутский Взвоз-І в Верхнем Приобье: опыт междисциплинарного изучения: коллективная монография. Барнаул, 2016. 270 c.

17. Кирюшин Ю.Ф., Грушин С.П., Тишкин А.А. Березовая Лука - поселение эпохи бронзы в Алейской степи. Барнаул, 2011. Т. II. 171 с.

18. Борисов В.А. Опыт разработки и применения экспериментальных методов исследования керамики (по материалам эпохи бронзы Верхнего Приобья). Кемерово, 2013.254 с.

19. Мыльникова Л.Н., Грушин С.П. Физико-химическое исследование керамики поселения Березовая Лука // Роль естественнонаучных методов в археологических исследованиях. Барнаул, 2009. С. 81-84.

20. Грушин С.П. Гончарное производство населения елунинской культуры эпохи ранней бронзы Верхнего Приобья // Известия Алтайского государственного университета. 2011. № 4-1. С. 60-67.

Исследование проведено за счет гранта правительства РФ (постановление N220), полученного ФГБОУ ВО «Алтайский государственный университет" договор № 14.Z50.31.0010, проект "Древнейшее заселение Сибири: формирование и динамика культур на территории Северной Азии».

\title{
TECHNOLOGICAL ANALYSIS OF EARLY BRONZE CERAMICS OF SHAUKE 1 SETTLEMENT
}

\begin{abstract}
Rakhimzhanova Saule Zhangeldyevna, postgraduate student of Department of Archaeology, Ethnography and Museology Altai State University (Barnaul, Russian Federation)
\end{abstract}

\footnotetext{
Abstract. The paper introduces the first results of special technical and technological investigation of ceramic artifacts discovered during the excavations of the Early Bronze Age settlement Shauke 1 located in the Pavlodar Region of North-East Kazakhstan. The research of ceramic objects is conducted within historical and cultural approach following A.A. Bobrinsky's technique. 53 samples from different vessels were selected for the technological analysis of ceramic artifacts found at the settlement. The samples were investigated with the use of a binocular microscope MBS-10. The main objective of the research was to identify cultural traditions at a preparatory stage of ceramic vessels production. The author studied initial raw materials selection skills and forming substance preparation. The author recorded the use of several conditional «spots» as sources of raw materials. Six different recipes of forming substances were identified at the settlement of Shauke 1 . The most common amongst them are «clay + chamotte + organic solution» $(60,38 \%)$, «clay + chamotte + bone + organic solution» $(28,30 \%)$. This indicates the presence of artisans who followed different traditions of pottery production at the site.

Keywords: Early Bronze Age; Shauke 1 settlement; Northeast Kazakhstan; ceramics; historical and cultural approach; A.A. Bobrinsky's technique; technological analysis; preparatory stage of production; feed stocks; forming masses; potter's traditions.
} 